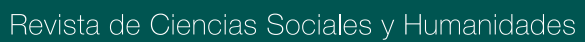

Número 10 / ABRIL, 2020 (25-40)

Marcos Noé Pool Cab

marcos.pool@correo.uady.mx

Universidad Autónoma de Yucatán,

Facultad de Ciencias Antropológicas, Mérida.

Yucatán, México

ORCID:

http://orcid.org/0000-0003-4326-5984

\section{IDENTIDAD, PERSONA Y PERSONHOOD ENTRE LOS MAYAS PREHISPÁNICOS}

\section{IDENTITY, PERSON AND PERSONHOOD} AMONG PREHISPANIC MAYAS

DOI:

https://doi.org/10.37135/chk.002.10.02 
Número 10 / ABRIL, 2020 (25-40)

IDENTIDAD, PERSONA Y PERSONHOOD ENTRE LOS MAYAS PREHISPÁNICOS
IDENTITY, PERSON AND PERSONHOOD AMONG PREHISPANIC MAYAS

\section{Resumen}

El trabajo que se presenta tiene como objetivo general explorar desde una visión actual las identidades mayas en la época prehispánica. De este objetivo general se desprenden dos objetivos particulares que dan cauce a la investigación: 1) estudiar de manera distinta a la de la antropología tradicional, el tema de la identidad y la persona en arqueología; 2) entender como la élite gobernante maya construía sus identidades y personalidades. El proceso metodológico que se siguió para la elaboración del presente estudio fue el siguiente: contrastación teórica del concepto personhood (personidad), en comparación con otras categorías como identidad individual y persona, búsqueda de indicadores desde diferentes recursos disciplinarios, cruce de información interdisciplinaria. La información empírica utilizada procede de contextos mortuorios, espacios y ajuares, todos éstos estudiados desde la arqueología; parte fundamental fueron los epítetos estudiados desde la epigrafía, así como símbolos y representaciones comprendidos desde la iconografía. Todo este proceso dio como resultado entender como los gobernantes mayas del periodo Clásico (300-900 d.C.) construían sus identidades y sus personalidades, específicamente en ciudades como Calakmul, Ekbalam, Yaxchilan, Copán y Oxtancah.

Palabras clave: Arqueología, mayas, persona, personalidad.

\section{Abstract}

The present study has as a general objective to explore the Mayan identities during pre-Hispanic times from a current perspective. From this general objective, two particular objectives give rise to this research: 1) Study it differently compared to traditional anthropology, the issue of identity and the person in archeology. 2) Understand how the Mayan ruling elite built their identities and personalities. The methodological process that was followed for the preparation of the present study was the following: theoretical contrast of the personhood concept, compared to other categories such as individual identity and person, search for indicators from different disciplinary resources, cross-disciplinary interdisciplinary information. The empirical information used comes from mortuary contexts, spaces and tombstones, all of them studied from archeology; fundamental part were the epithets studied from epigraphy, as well as symbols and representations comprised from iconography. This whole process resulted in understanding how the Mayan rulers of the Classic period (300-900 AD) built their identities and personalities, specifically in cities such as Calakmul, Ekbalam, Yaxchilan, Copan and Oxtancah.

Keywords: Archeology, maya, person, personality. personhood. 


\section{INTRODUCCIÓN}

Tradicionalmente los estudios de identidad en las ciencias sociales han sido abordados desde lo colectivo. Basta con hacer una revisión de los trabajos llevados a cabo en torno a la identidad, en el caso de México, para darnos cuenta de esta tendencia. Como ejemplo podemos mencionar el libro I Seminario sobre Identidad de Leticia Irene Méndez y Mercado (1992). Dicho texto fue resultado de la reunión de discusión y diálogo efectuada en el marco de la XXII Mesa Redonda de Antropología de la Sociedad Mexicana de Antropología, celebrada en Mérida, Yucatán.

Otro trabajo valioso es el editado por Héctor Hernández Álvarez y Marcos Noé Pool Cab (2010), Identidades y Cultura Material en la Región Maya, derivado de un simposio organizado por los mismos autores con motivo de la 73rd Annual Meeting de la Society for American Archaeology, llevado a cabo en Vancouver, Canadá, en 2008; en este trabajo varios investigadores abordan temas de etnicidad, género, edad, espacio, a partir de los datos arqueológicos, bioarqueológicos, zooarqueológicos y documentos escritos.

El enfoque colectivo que ha tenido el estudio de la identidad forma parte de la tradición antropológica, condicionado en parte con la distancia que ha mantenido la antropología con otras disciplinas como la psicología, que también trata el tema. Hoy día, con las propuestas posmodernas existe más diálogo entre estas dos disciplinas, que resulta cada vez en un mayor acercamiento, referente al estudio de la identidad.

El trabajo que a continuación se expone va más allá de ver la identidad en un sentido colectivo, como tradicionalmente se ha venido realizando en el campo antropológico y arqueológico; más bien se propone que es posible entender las identidades y personalidades particulares, a través de un soporte teórico-metodológico adecuado. En este caso mediante la aplicación del concepto personhood, que será previamente explicado, antes de utilizarlo para entender las personalidades e identidades de los gobernantes mayas del pasado. Finalmente, vale la pena comentar que el tema del presente ensayo ha sido poco abordado en la arqueología maya, lo que lo hace un campo de estudio potencialmente vasto, por el tipo de información que hoy existe.

\section{METODOLOGÍA}

El presente artículo de investigación es resultado de un estudio teórico comparativo y aplicativo de carácter interdisciplinario. El primer paso es el análisis de una categoría poco utilizada en la arqueología en general y en la maya en particular. Apostando a su pertinencia, el estudio obedece a la búsqueda y aplicación de un concepto que evite la carga occidental. Es por ello que se compara con otras categorías de mayor tradición en el campo antropológico, tales como la identidad y la personalidad, pero que desde mi punto de vista no consideran la conformación del individuo y la persona desde contextos particulares, no occidentales. Por lo mismo, se recurre en primera instancia a una categoría surgida de la etnografía con enfoque posmoderno y que ha sido estudiada y utilizada en otros contextos como los melanesios e hindúes, el término personhood. Para autores como Fowler (2004) dicho concepto sirve para diferenciar a la persona no occidental de la occidental, por lo que, en el presente caso, es de particular utilidad para estudiar a la persona desde el contexto arqueológico y prehispánico maya.

Aun cuando el personhood no es una categoría surgida de estudios arqueológicos, tal como es comprendido, puede ser aplicado de manera consistente, y es muy útil para la interpretación del dato arqueológico. Entonces un análisis y estudio de la persona en el pasado prehispánico se puede llevar a cabo con mayor solidez y menor sesgo occidental.

Para lograr este cometido se recurrió a contextos que debían tener ciertas características, que, si bien han sido estudiados con anterioridad, no con los objetivos que se persiguen en el presente trabajo. Por lo mismo fue de importancia la búsqueda de contextos registrados con la información per- 
tinente, tales como espacios, objetos personales, representaciones simbólicas y epítetos en relación con las personas analizadas. Tal información se obtuvo en los contextos de élite, el de los gobernantes mayas del periodo Clásico de las tierras bajas mayas.

Para el análisis e interpretación fue necesario el cruce de información interdisciplinaria. Por lo mismo, el presente trabajo resulta en un acercamiento de información diversa proveniente de la etnografía, la epigrafía, la iconografía y la arqueología. En la tabla 1 se sintetiza el proceso metodológico seguido en el estudio.

\section{RESULTADOS Y DISCUSIÓN}

\section{LA IDENTIDAD Y EL INDIVIDUO EN LA FILOSOFÍA DEL SUJETO DE RICOEUR}

En torno al estudio de la identidad individual se han desarrollado en las ciencias sociales diferentes propuestas de investigación referentes al género, la sexualidad, el cuerpo, la persona, la personalidad y el agente, por mencionar las más importantes. Entre estos estudios, sobresale la reflexión hermenéutica que hace Paul Ricoeur (2003) (pues ha trascendido más allá de la historia) sobre el yo de la conciencia y el yo de la experiencia. La preocupación central de este autor es la autocomprensión, el cogito o la filosofía del sujeto.
En el libro Soi-meme comme un autre (sí mismo como otro) Ricoeur (2003) menciona tres intenciones: 1) el uso lingüístico del sí en diversas lenguas naturales, 2) la doble significación del mismo (idem/ipse) y 3) la oposición entre sí y otro. Para este autor la identidad personal es una relación dialéctica entre ipseidad y mismidad.

Según Ricoeur (2003), la mismidad (o identidad idem) es un concepto de relación y una relación de relaciones. Para entenderlo menciona tres criterios de identidad y son:

1.- La identidad numérica, el ser una y la misma persona o cosa.

2.- De semejanza extrema o sustitubilidad, en un sentido cualitativo.

3.- De permanencia continua o permanencia en el tiempo.

Los anteriores criterios pueden ser entendidos cuando pensamos en una persona que en el transcurso de su vida sufre diferentes cambios anatómicos, fenotípicos y de carácter, pero no por ello deja de ser la misma. En el transcurso de este tiempo el sustrato permanece. La mismidad implica la cualidad del ser mismo aun cuando hayan ocurrido cambios a través del tiempo. Menos claro en su explicación es la que hace sobre la identidad ipse o ipseidad. En pocas palabras se refiere a pensar el sí mismo como otro. Para Ricoeur, nadie se configura a sí mismo por su cuenta y riesgo, es frente a la solicitud del otro que me convierto en alguien. La ipseidad del sí mismo implica una forma de permanencia en el tiempo y vincula las preguntas ¿quién soy? con ¿qué soy? (Ricoeur 2003). Soy alguien, pero también soy algo.

Tabla 1: Proceso metodológico utilizado en el estudio

\begin{tabular}{|l|l|}
\hline Contrastación del concepto personhood & Análisis y comprensión \\
\hline Búsqueda de información pertinente: & $\begin{array}{l}\text { Espacios, objetos considerados como persona- } \\
\text { les, representaciones simbólicas, epítetos de la } \\
\text { persona estudiada } \rightarrow \text { Contextos de élite }\end{array}$ \\
\hline Recursos disciplinarios utilizados: & Arqueología, etnografía, epigrafía, iconografía \\
\hline
\end{tabular}

Fuente: Elaboración propia 
En el sujeto, nos menciona Ricoeur (2003), se relacionan dos conceptos de la mismidad que forman la particularidad de base o primitiva, estos son el cuerpo físico y la persona psíquica. La persona tiene cuerpo y el cuerpo tiene a la persona. Sin embargo, el individuo es más que solo la combinación de las particularidades corporal y psíquica. El individuo es tal en cuanto actúa, o sea, en cuanto entra al plano de la agencia y se hace dueño de las acciones, como agente. Por tanto, cuerpo, psique y acción conforman al individuo.

Los estudios posmodernos se han dado a la tarea de explicitar ciertas categorías que entran en juego al momento de entender la identidad individual. Por lo que vale la pena en este momento comentarlas.

\section{PERSONA Y PERSONHOOD}

Chris Fowler (2004), en la introducción del libro The Archaeology of Personhood. An anthropological approach, diferencia entre person (persona) y personhood. El término person o persona es usado para referirse a una entidad que puede ser humana o de otro tipo. La persona occidental se piensa componiéndose de varios aspectos que se asocian temporalmente. Estos aspectos pueden ser la mente, el espíritu, el alma o bien el cuerpo físico, y denota la entidad como una forma de agencia, en su calidad unívoca. Quien puede ser o qué puede ser una persona, varía con el contexto. El personhood, por otra parte, es de una amplia definición y se refiere a la condición o estado de ser persona, tal como es entendido en cualquier contexto específico. Esta idea de persona se diferencia a la de Ricoeur, en cuanto trasciende al individuo, pues puede aplicarse también a lo no humano. En este caso, cualquier elemento de la naturaleza puede ser persona, las rocas, las montañas, los árboles, la tierra, cualquier tipo de objeto.

Las personas están constituidas, reconstituidas, mantenidas y alteradas en las prácticas sociales a través de su vida y después de la muerte. El personhood se comprende, como la condición que implica cambios constantes, transformaciones que se producen en la persona en vida y en muerte, la persona permanece. La gente puede pasar de un estado de personhood a otro, se alcanza y se mantiene no solo a través de las relaciones con otros seres humanos, también con las cosas, lugares, animales y las características espirituales del cosmos (Fowler 2004). Como la cualidad de ser persona no solo aplica a lo humano, tenemos que hacer la distinción conceptual entre el personhood humano y el personhood no humano. Me parece importante esta distinción porque es común la confusión en no pocos investigadores acerca del término, pues equiparan personhood con personalidad, lo que es un error.

La persona humana tiene personalidad, pero es cambiante a través del tiempo y en determinadas circunstancias y condiciones. La personalidad es en vida, no es en muerte, este es el carácter de su personhood, por tanto, igual se entiende en términos de personalidad. Pero en el caso de lo no humano, el término puede ser utilizado (en el castellano) como personidad y no como personalidad. Personidad es un neologismo que se entiende como calidad de ser persona a lo que no es persona (en términos humanos) pero se le entiende y se le trata como tal. También es una condición o estado de ser persona en un contexto específico.

En el caso del personhood humano, la persona es constituida, deconstituida, mantenida y alterada en las prácticas sociales a través de la vida y después de la muerte (Fowler 2004:7). Mientras que el término personalidad es una categoría netamente humana, el término personidad traspasa el ámbito de lo humano como categoría transhumana y puede abarcar la naturaleza, las cosas, los espacios y dimensiones que afectan las identidades humanas.

Ahora bien, las personas se comportan dentro una lógica de acuerdo al contexto social. Las tendencias de comportamiento a largo plazo se apoyan en esa lógica y también afectan la forma de relacionarse. Estos son los llamados modos o campos del personhood. La gente participa activamente de estas tendencias cuando persigue estrategias de interacción. Como resultado de esta interacción cada persona se constituye de un modo específico (Fowler 2004).

La gente contemporánea o actual, que se inserta dentro de una dinámica globalizadora, tiene ciertos modos de personhood que los caracteriza. Se- 
gún Fowler (2004) los rasgos fundamentales de los modos de personhood contemporáneos son la individualidad e indivisibilidad, individuo, dividuo y dividualidad, categorías teóricas que surgen de la deconstrucción de la forma tradicional en la que ha sido abordado el individuo en las ciencias sociales.

La individualidad, en la concepción común, se refiere a la singularidad personal. Fowler (2004) utiliza el término individualidad para referirse al estado unitario, totalizado e indivisible de una persona. La indivisibilidad es una tendencia predominante en el modo del personhood occidental y contemporáneo. La individualidad es fija y libre.

Todos somos individuos en el uso común del término. Sin embargo, el término individuo es utilizado para referirse al personhood, en el que una constante individualidad y una persistente identidad personal se destaca más que las identidades relacionales. Toda la gente tiene individualidad, pero la forma que toma, los deseos que la caracterizan y el valor, varía inmensamente.

Ahora bien, todo individuo está conformado por diversos rasgos que tienen orígenes diversos, como la mente, el cuerpo y el alma. Todos estos rasgos además son compartidos. Lo que yo soy es resultado de la interacción con otros, quienes a su vez también interactúan y comparten rasgos con otros, como las características físicas que me identifican con mis parientes. Mis rasgos constitutivos se los debo a otros y con ello quiero decir que la identidad individual se construye por la relación que se tiene con otras gentes y por lo tanto los rasgos constitutivos de esta identidad no pueden ser considerados como netamente propios. El individuo entonces deja de serlo y pasa a ser visto como dividuo caracterizado ya no por la individualidad sino por la dividualidad (Fowler 2004:8).

El dividuo es el estado de ser en el que la persona es reconocida como compuesta por múltiples autorías. La constitución de la persona es finalmente resultado de varios orígenes. Lo que caracteriza a una persona es resultado de su interacción con otras personas. La personalidad se construye precisamente gracias a esta interacción. Finalmente, lo que yo soy se lo debo a los demás, ¿será que ya no soy yo, si no que soy como los otros? Soy un dividuo y lo que me caracteriza es la dividualidad.

Los ejemplos del persohood dividual que Fowler (2004) discute son la partibilidad en contextos melanesios y la permeabilidad en contextos hindúes. En pocas palabras, la partibilidad es un estado de ser en el que la persona dividua está reconfigurada de tal forma, que una parte de ella se puede extraer y dar a otra persona a la que se debe. Las partes de uno mismo pertenecen originalmente a otras personas, por lo que pueden ser identificadas como objetos y ser extraídas.

La permeabilidad, por otro lado, es un estado de ser en el que el dividuo puede ser penetrado por las cualidades que influyen en la composición interna de la persona. Las partes componentes de la persona no son identificables como objetos sino como sustancias fluidas.

Todos esos modos de personhood son construcciones, pero tal como menciona Fowler (2004), en la actualidad el individuo indivisible tiene mayor presencia en la imaginación arqueológica. Generalmente no se trata a las personas como dividuos, aun cuando los diferentes modos de personhood pueden ser útiles para entender y explicar la identidad de hombres, mujeres y niños estudiados en la arqueología mesoamericana.

\section{LA CONSTRUCCIÓN DEL PERSONHOOD Y LA IDENTIDAD EN LOS GOBERNANTES MAYAS DEL PERIODO CLÁSICO (300-900 D. C.)}

Gracias a que los estudios antropológicos han vuelto la vista a los individuos, como personas, como agentes, los estudios sobre el personhood, así como sus modos o campos, son posibles también de abordar. En arqueología maya se tienen las fuentes empíricas para llevar a cabo este tipo de estudios. Me refiero a las inscripciones epigráficas, las representaciones iconográficas y los contextos mortuorios.

Los gobernantes mayas son individuos posibles de estudiar utilizando las categorías discutidas por Ricoeur (2003) y Fowler (2004), mencionados líneas atrás. El sí mismo y la persona son categorías 
difíciles de separar porque al final son categorías de la mente humana. No obstante, pueden distinguirse en su interacción con los demás y con el compromiso público. En este sentido, el sí mismo tiene menor compromiso público que la persona (Colas 2003:269). La relación del sí mismo con la persona se puede observar de manera clara en los reyes o gobernantes.

Una interesante disertación sobre el personhood y la persona, aplicados en los nombres de dignatarios mayas prehispánicos, aparece en un trabajo de Pierre Colas (2003): K'inich and King. Naming self and person among Classic Maya rulers, publicado en la revista Ancient Mesoamerica. En este trabajo, el autor realiza un análisis histórico de los conceptos y menciona que, en la cultura occidental medieval, el sí mismo y la persona eran llamados cuerpo natural y cuerpo político, respectivamente.

Colas (2003), citando a Kantorowicz (1957), dice que el cuerpo natural constituía la parte mortal del rey, el cuerpo político estaba relacionado con el espíritu santo y los ángeles (Kantorowicz 1957:89). El rey entonces era una unidad indivisible y singular, modos del personhood que según Fowler (2004) son típicamente occidentales. El sí mismo en el individuo humano se refiere a aspectos que pueden ser percibidos por la sociedad, mientras que la persona en estos casos se refiere a la interacción del individuo con la sociedad, es su identidad social.

Colas (2003) menciona que, en civilizaciones antiguas, el sí mismo de los reyes o gobernantes y sus personas debía ser legitimado. El vehículo principal de esta legitimación fue la religión a través de la cual se establecía comunicación directa o indirecta con los dioses. Un gobernante o un rey podía divinizarse, afirmar su especial relación con otro ser divino y al mismo tiempo diferenciarse de los otros seres humanos mediante tres estrategias:

1.- A través de los rituales. En estos, el gobernante era transformado en un ser sobrenatural con la asistencia de materiales, tales como máscaras de deidades, ropa y ornamentos, dioses y reyes se unen en una identidad absoluta. El rey entonces llega a ser el centro de las ideas religiosas proyectadas por él mismo a la sociedad. El rey, en su papel de dios, se ha moldeado en el repositorio de creencias religiosas de su sociedad, es una figura central que se ha configurado aparte (Hocart 1970:99). Este tipo de ritos no solo se llevan a cabo en la vida de los gobernantes, también se realiza en su muerte.

2.- Otra forma de legitimación de los gobernantes era afirmando su ascendencia divina. Los textos jeroglíficos del Clásico maya conectaban a los gobernantes o reyes con sus distantes ancestros, estableciendo con ello una ascendencia divina y legitimando su gobierno (Colas 2003:270). Tal es el caso en lugares como Palenque, Tikal, Calakmul, Chichén Itzá, entre otros.

Las relaciones de los mayas del periodo Clásico muestran con claridad a los antepasados como testigos de acontecimientos importantes durante épocas de transición. Los antepasados participaban en las coronaciones reales y también en las ceremonias de designación de heredero. Pero los antepasados no eran importantes solamente en periodos problemáticos.

Los muertos eran danzantes en fiestas de cumpleaños en Piedras Negras (Fitzsimmons 1998), fundadores de templos y plataformas domésticas, y espíritus conjurados a los que los grupos de la élite consultaban durante los días importantes del calendario o en ocasiones ceremoniales.

3.- Un tercer método de legitimación, menciona Colas (2003), era utilizando epítetos que procedieran de alguna deidad, o de algún ancestro histórico o mitológico, asociándose de esta forma con el ser divino. Así el gobernante adoptaba parte de la identidad del dios o de su ancestro, que es lo mismo decir que adoptaba parte de su esencia.

\section{CONSTRUCCIÓN DEL PERSONHOOD A TRAVÉS DE OBJETOS, NOMBRES Y PRÁCTICAS}

A continuación, veremos cómo a través de los procesos de legitimación los gobernantes y señores importantes mayas, construían y deconstruían su personalidad e identidad. En la figura 1 se muestra la ubicación de los sitios arqueológicos que se mencionan en la presente discusión. 
Fuente: http://www.latinamericanstudies.org/maya-map.jpg (Modificado)

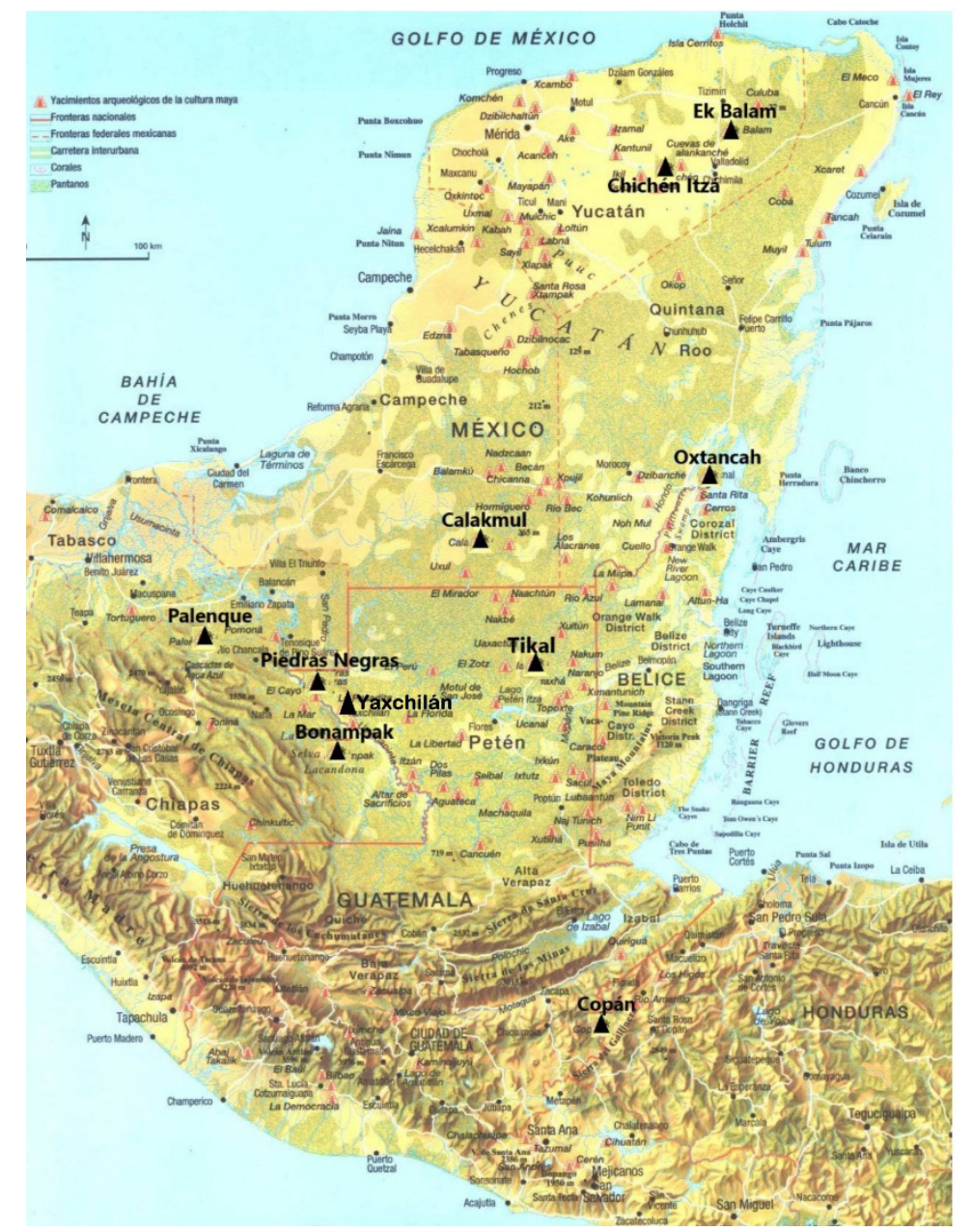

Figura 1: Sitios arqueológicos mencionados en el presente artículo

Rasgos peculiares en los rituales son los ornamentos, como los mascarones y prendas de vestir utilizados normalmente en rituales funerarios. James Fitzsimmons (2003) menciona, por ejemplo, que en el Altar 5 de Tikal se puede ver a Jasaw Chan K'awiil y a un ajaw de Maasal vestidos con ropa decorada con símbolos relacionados a la muerte, debido a que este monumento registra la consagración de los restos humanos de la señora Tuun Kayawak por el rey y su vasallo, que imita un aspecto del dios A, el dios de la muerte (Fitzsimmons 2003:674).

Fitzsimmons (2003), reporta que, aparte de las actividades en las tumbas, existen ejemplos de mascarones o ropa de muerte en rituales de conjuro. Tal es el caso del Dintel 25 de Yaxchilan -con dos mascarones- que describe el conjuro de un ser sobrenatural, Aj K'ahk' O' Chaak por la señora
K'ab'al Xook. Las semejanzas entre el ritual y la ropa son claras pues al parecer son idénticos los tres ciempiés o ciempiés-serpientes asociados al pelo y mano de la señora $K^{\prime} a b$ 'al Xook (Fitzsimmons 2003:675).

En trabajos realizados por Ramón Carrasco en $\mathrm{Ca}$ lakmul (Campeche), han sido reportados mascarones o ropa mortuorias, tal es el caso de la Tumba 4 de la Estructura 2 donde se encontró una máscara de jade (Martin \& Grube 2000). En esta máscara se describe el artefacto como el b'aah (imagen o cabeza) de Yuknoom Ch'een II de Calakmul, pero se recuperó en la tumba de su sucesor (posiblemente su hijo), Yuknoom Yich 'ak K'ahk'. Houtson y Stuart (1996) mencionan que el glifo b'aah tiene varios usos:

1) es una referencia literal a la imagen o cabeza de 
una persona;

2) como una metáfora para la persona principal de un sitio;

3) como alusiones a representaciones físicas de la imagen.

Houston y Stuart proponen que el uso de la palabra $b$ 'aah en las inscripciones sugiere una creencia similar al tonalli que es un tipo de alma en el Centro de México. En todo caso, si es un aspecto del alma o no, parece que la máscara de Yuknoom Ch'een con Yuknoom Yich 'ak K'ahk' apoya la idea de que este último imita a su antecesor y utiliza su $b$ 'aah, $o$ imagen de un rey ya muerto. También puede indicar que dicho rey vive en su sucesor y que, en este sobrevive la esencia del antecesor, reafirmando con ello su persona (Fitzsimmons 2003:675).

En los enterramientos prehispánicos es común encontrar restos de individuos acompañados de objetos o cosas, relacionando con ello la vida después de la muerte. Tradicionalmente han sido considerados estos contextos como ejemplo de la persona social del individuo, siguiendo con ello a Binford (1971). Pero no solo la persona social en vida refleja también el cuerpo político indivisible a la persona social (mortal); dicho cuerpo político está cargado de expectativas que se supone el individuo cumplió en vida y que lo seguirá caracterizando después de la muerte.

Un trabajo que trata de entender el personhood en los contextos funerarios es el de Mayté Graniel Toraya (2012) denominado Estudios del personhood en las Tierras Bajas Centrales Mayas durante el Clásico. En su tesis, la autora analiza varios contextos funerarios y examina, específicamente, los componentes o relaciones entre las personas y sus identidades. Graniel (2012) toma como muestra los enterramientos de varios sitios entre los que se encuentra Calakmul.

El entierro 1 de la estructura III de Calakmul presenta entre su ajuar una máscara funeraria y una vasija antropomorfa. Las características del ajuar hacen pensar en la representación del individuo enterrado personificando al dios L. Graniel (2012) menciona que el resto del ajuar funerario estaba constituido por una gran cantidad de conchas y un medallón que posiblemente representaba a un jaguar (otra dualidad posible del gobernador). A decir de la autora, la máscara y el medallón eran la representación dual del gobernante, como dios y como animal.

Vale la pena recordar que el jaguar es un símbolo de poder y muchos gobernantes mayas utilizaban este epíteto para identificarse, pero también puede no solo estar hablando del cuerpo político, también puede estar indicando su esencia anímica animal, espiritual. Al respecto, hay que mencionar que entre los mayas actuales -y posiblemente también en el prehispánico- existe la creencia en la existencia de personas con características mágicas de poder llamados Uayes, quienes tienen el poder de transformarse en cosas o animales, pues detentan el espíritu del mismo.

Podemos hablar entonces de la representación de un código sustancia. Martín (2013) señala que el código-sustancia se obtiene de alguna otra persona, un objeto o animal. La persona receptora puede procesar esta esencia dentro de ella, y convertirla en parte de sí mismo, complementando de esta manera su personalidad (Martín 2013:80).

Graniel (2012) concluye que la presencia de los objetos como la máscara y el medallón son indicadores de la dividualidad divisible (o partible) del personaje enterrado (ver también Fowler 2004). Los objetos encontrados en el entierro 1 de la estructura III de Calakmul, con seguridad debieron ser utilizados en los rituales donde el personhood era legitimado.

Otro ejemplo que describe Graniel (2012) es el entierro 1 del edificio IIH de Calakmul. La presencia de cinabrio en los huesos, indica, para la autora, distribución del flujo de sangre en el individuo fallecido. El cinabrio puede entenderse como la sustancia que se aporta socialmente para mezclarse con el flujo de sustancias pertenecientes al difunto, lo que indica la dividualidad permeable, de acuerdo con Fowler (2004).

La autora, citando a Rivera Dorado (1981) menciona que el cinabrio es un líquido vital que entraña el renacimiento. Las características del contexto implican que el cuerpo del individuo pasó por rituales funerarios para su transformación y, por 
ende, la reconfiguración de su persona.

Colas (2003) es uno de los escasos investigadores que ha estudiado el significado de un teonimio (nombre de un dios), utilizado como nombre personal por ciertos gobernantes mayas. Me refiero al nombre k'inich, el nombre del dios del sol durante el periodo Clásico.

El sol siempre fue llamativo como identificación de los gobernantes en civilizaciones de la antigüedad, como los egipcios y los mesopotámicos. Dichos gobernantes reproducían en su persona social, la función, la energía y la presencia constante o eterna de este astro, como cualidades esenciales.

Como demuestra Colas (2003), el teonimio k'inich fue usado en dos modos por los gobernantes mayas: por un lado, sirvió para realzar al gobernante mismo (su sí mismo) y por otro para exaltar el poder y el estatus divino referente a su persona. El término $K$ 'inich no solo es el sol, también es el rey en persona, el sol es persona.

El sí mismo del gobernante o rey representaba un aspecto especial del dios sol. La persona del rey se refirió por el nombre $k$ 'inich como prefijo del nombre real del rey (Colas 2003:271, 281). Adoptar lo que podemos considerar como esencia ancestral, también se manifiesta en otros individuos de la élite como los escribas, tal como se observa en Copán (Fash 1991 en Pool 2003) y que a continuación se describe.

Asentado prominentemente al sur del sitio de Copán, se levanta la Plaza A que contiene varias estructuras del siglo VIII d. C. En el centro del lado sur de esta plaza se encuentra la estructura $9 \mathrm{~N}-82$, un suntuoso edificio abovedado ornamentado con mosaicos, esculturas y una elaborada banqueta jeroglífica en el cuarto central. Esta estructura fue para los arqueólogos del Proyecto Arqueológico Copán un ejemplo de patrones de linaje y adoración de los ancestros (Fash 1991:68).

Los trabajos de excavación y análisis iconográfico dieron como resultado la identificación de un personaje llamado Ahau Kin, cuyo registro epigráfico se encontró en la escalera jeroglífica de la estructura $9 \mathrm{~N} 82 \mathrm{C} 1$ st. Otro descubrimiento en las excavaciones estuvo relacionado con este personaje.
En el relleno constructivo de la misma estructura se encontró una escultura que, de acuerdo a sus rasgos, fue identificada como un Pauah Tun (gorro tejido) y considerado en Copán como deidad de los escribas. Dicha escultura se observa en la figura 2.

Fuente: Fash 1991
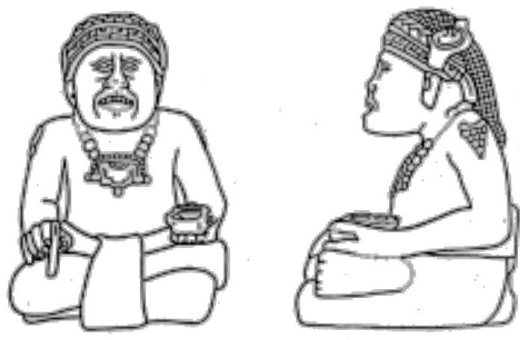

Figura 2: Pauah Tun encontrado en el relleno de la Estructura 9N-82C-1st

La escultura fue decapitada, la cabeza quemada y ambas partes fueron arrojadas en el relleno durante la construcción de la 9N-82C-1st. Según Fash (1991), esto sugiere que dicha escultura estuvo originalmente en uso en la ahora destruida construcción temprana $(9 \mathrm{~N}-82 \mathrm{C}-2 \mathrm{nd}$.), y ritualmente muerta y enterrada cuando la construcción fue abandonada (Fash 1991:73). Las características de la escultura también se observan en los bustos de los nichos de la estructura que fue erigida y dedicada a Ahau Kin (Fash 1991 en Pool 2003).

Fash (1991) asume que existe una estrecha relación o asociación entre los motivos de lirios de agua y la fachada de estructura $9 \mathrm{~N}-82 \mathrm{C}-1 \mathrm{st}$, y el considerado Pauah Tun de la 9N-82C-2nd, como se observa en la figura 3. 


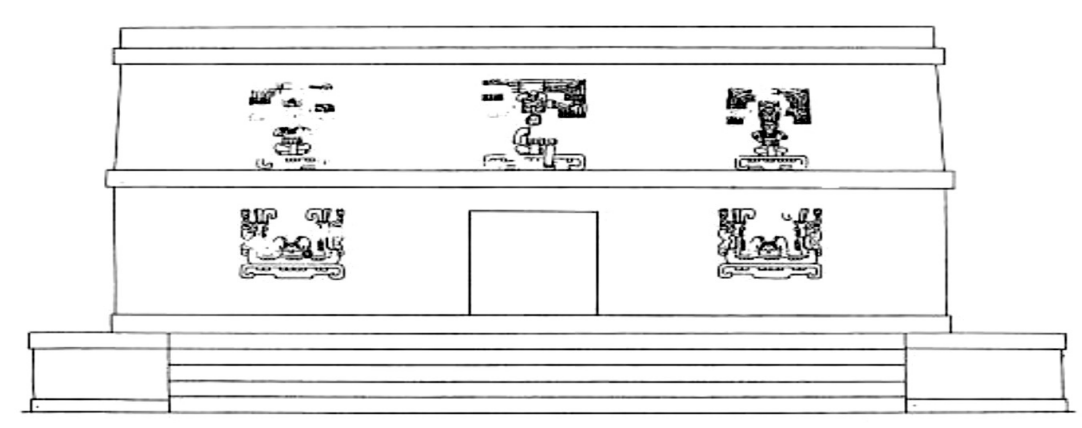

Figura 3: Reconstrucción hipotética de la fachada norte de la Estructura 9N-82C-1st

Sugiere también que Pauah Tun está relacionado con los lirios de agua y los motivos que adornan la figura central de la fachada norte, tal como se aprecia en la figura 4.

Estos motivos, explica Fash (1991), son usados para asociar este individuo con su patrón sobrenatural, el Pauah Tun como patrón de los escribas y artistas. Esta idea la apoya Fash al asociar los datos iconográficos y escultóricos con el texto de la banqueta jeroglífica del cuarto central de la estructura $82 \mathrm{C}-1$ st. El protagonista de esta inscripción está referido como ya se mencionó a Ahau Kin, quien fuera un astrónomo y a quien está dedicado el templo.

Fash (1991) cree que los rasgos distintivos y la prominente colocación de la figura central en el tablero de la fachada significa que esta figura describe al protagonista de la banqueta. También hace énfasis en la iconografía del Pauah Tun/Bacab, que puede ser visto además en el gobernante representado en la Estela Norte, en el templo 21, en el templo 11 y en la estructura A, todos estos en Copán (Fash 1991:76-86).

Otro dato que Fash (1991) utiliza para apoyar la adoración a los ancestros en la misma estructura

Fuente: Fash 1991
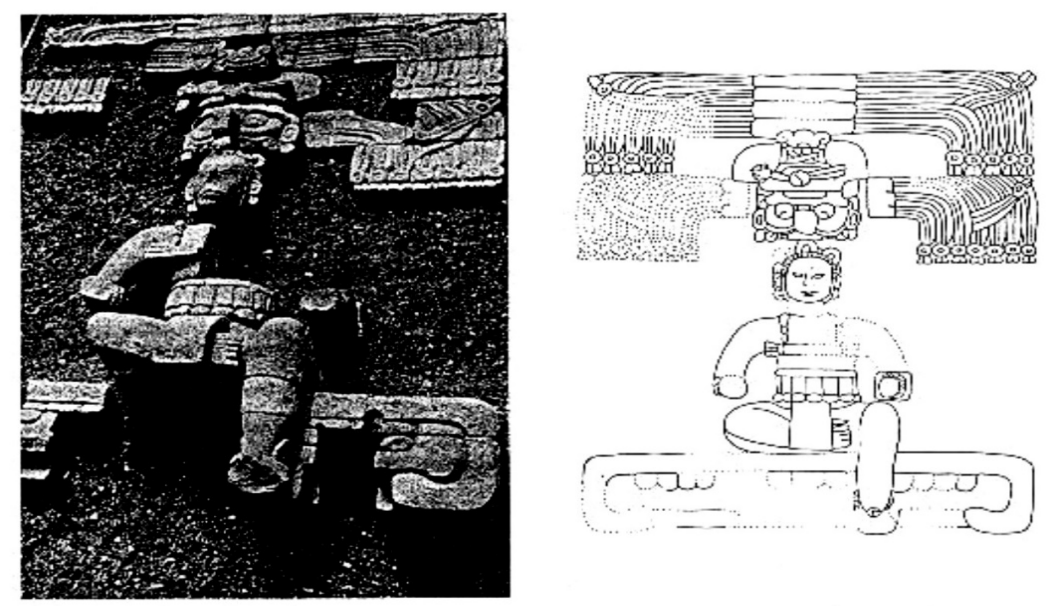

Figura 4: Figura central de la fachada norte de la Estructura 9N-82C-1st 
es el siguiente: debajo y enfrente de la esquina noreste de la estructura 9N-82C-2nd se encontró el entierro de un adulto masculino, el entierro VIII6 . Este individuo fue colocado en posición flexionada y provisto de tres cazuelas polícromas del Clásico Tardío y un pectoral de piedra verde de 16 centímetros de largo. A juzgar por la cerámica, la posición flexionada y el contexto estratigráfico, dicho entierro fue asociado en el momento de uso de la estructura $9 \mathrm{~N}-82 \mathrm{C}-2$ nd y a la temprana estatua del Pauah Tun/escriba.

El pectoral de piedra verde es virtualmente del mismo tamaño del cofre-receptáculo descrito en la figura central de la fachada norte de la estructura 9N-82C-1st. Fash (1991) cree que el entierro y la figura de la fachada central proveen evidencia de la adoración de los ancestros y la tradición de la perpetuación del linaje, con la nueva cabeza del linaje orgullosamente exponiendo la insignia del mismo patrón sobrenatural puesto por (y enterrado con) su escriba predecesor y ancestro (Fash 1991:78).

Como pueden observarse, las prácticas rituales, las representaciones iconográficas en un edificio, así como la materialización en una escultura, hacen de Ahau Kin un ser cuasi divino-humanizado, al manifestar simbólicamente su ascendencia. Esta esencia pudo haberle permitido fungir como puente entre los dioses y los seres humanos. Puede ser percibido como persona dividua. Otro ejemplo en el que la legitimación a través de los rituales, los epítetos y la ascendencia, forma parte de la construcción del personhood, se da en Ek Balam, con U Kit Kan Le'k Tok'.

Geiser Martín (2013) en su tesis de licenciatura, analiza las diferentes referencias arquitectónicas, escultóricas, iconográficas y lingüísticas para entender la personalidad del que fuera el principal gobernante de Ek Balam, entre los siglos IX y X d. C. Con respecto a la construcción de la persona de U Kit Kan Le 'k Tok', menciona el autor, existe evidencia que lo coloca como un importante personaje, tanto en vida como después de muerto.

Para iniciar, el nombre de este gobernante está íntimamente relacionado con diversos aspectos de la cosmovisión maya. Como el dueño de los cuatro pedernales, (una de sus connotaciones) se enmarca como un personaje que tiene la posesión y repercusión directa en los cuatro rumbos del universo (Martín 2013). Muy pocos gobernantes como este se le relacionan con varias deidades.

En Ek Balam, U Kit Kan Le 'k Tok', es mencionado como el señor de la casa del cielo. Se le representa en diversas imágenes con características y atributos del dios K'awiil, como dios joven del Maíz y como dios Itzamnna. De esta manera, legitimaba su status de gobernante cuasi divino al manifes-

Fuente: Vargas \& Castillo 2001:407,411, 415 en Martín 2013

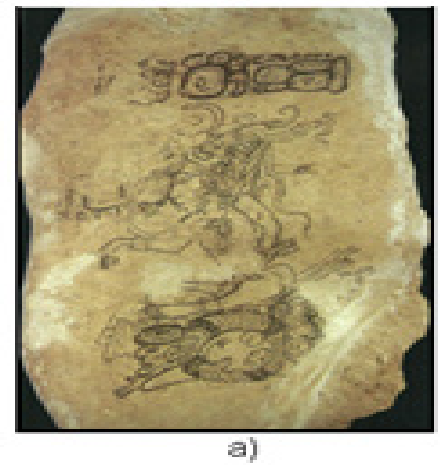

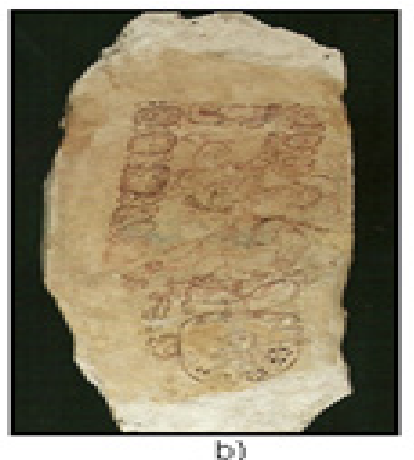

b)

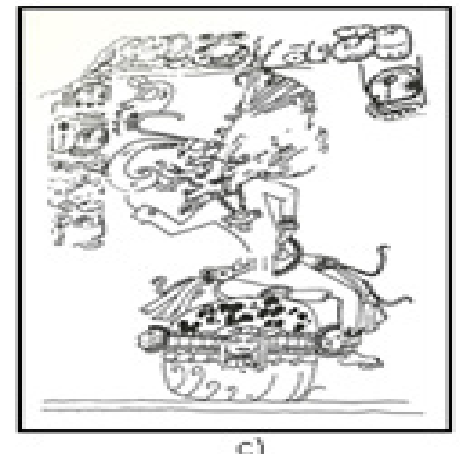

c)

Figura 5: Tapas de bóveda donde se representa a U Kit Kan Le’k Tok', como dios del Maíz (a) y el dios K'awiil 
tarse como un ser emblemático de las dinastías mayas, representando el renacimiento continuo y cíclico que da estabilidad, y como ser creador (Martín 2013:77).

Como se aprecia en la figura 5, dichas representaciones aparecen principalmente en tapas de bóveda, incluyendo la de su habitación y la de su tumba (Vargas \& Castillo 1999 en Martín 2013:72-73).

La esencia divina o cuasi divina del gobernante se refleja en su ajuar funerario. Al morir fue depositado sobre una piel de jaguar y estuvo acompañado por importantes ofrendas que contenían platos y vasos de cerámica y alabastro, jade, concha nácar, agujas de mantarraya, perlas, un pendiente de oro que representa una rana, pendientes de concha que representan calaveras, etc.

Algunos de los objetos del ajuar tenían inscripciones con el nombre del gobernante. Sobresalen como parte de la ofrenda los restos óseos de dos niños donde según (Vargas 2001:141 en Martín 2013) habrían servido de compañía en su viaje al inframundo.

Como ente divino, su viaje al inframundo también está representado por el lugar de la tumba que se encuentra en un cuarto posterior a la Estructura 35 Sub de la Acrópolis. Según se aprecia en la figura 6, la fachada está decorada de tal forma que representa las fauces del monstruo del inframundo.

De esta forma, el cuerpo depositado representa que este personaje se encuentra dentro de las fauces de este gran monstruo (Martín 2013). Este autor, citando a Vargas \& Castillo (2005) menciona:

Fuente: Vargas \& Castillo 2005: 58 en Martín 2013

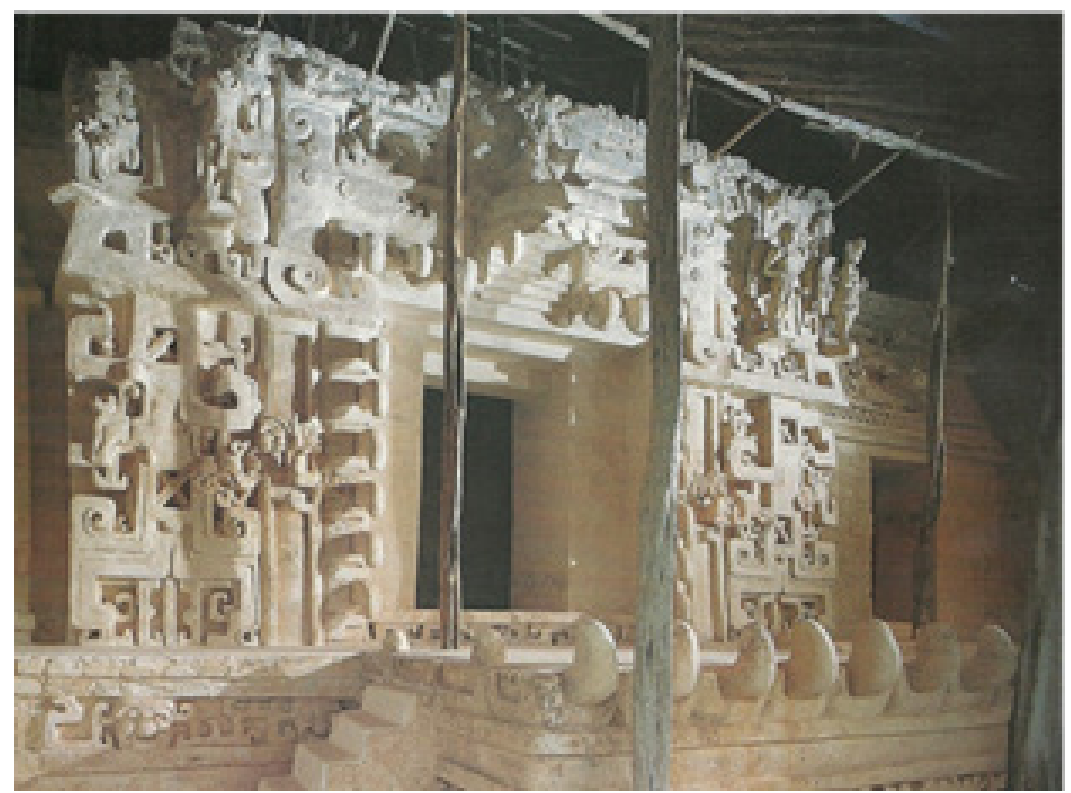

Figura 6: Estructura $35 \mathrm{Sub}$ de la acrópolis de Ek Balam 
Posterior a su muerte, U Kit kan Le'k Tok' es mencionado en otras inscripciones del sitio. Los gobernantes que le sucedieron hacían alusión a él como ancestro, para legitimar su estatus. Uno de ellos, su hijo Hun Pik Tok, menciona ser semejante a su padre, atribuyéndose de esta forma el personhood de $U$ Kit. La Figura 7 muestra la Estela 1 del sitio de Ek Balam donde está registrada dicha aseveración.

Fuente: Lacadena 2003
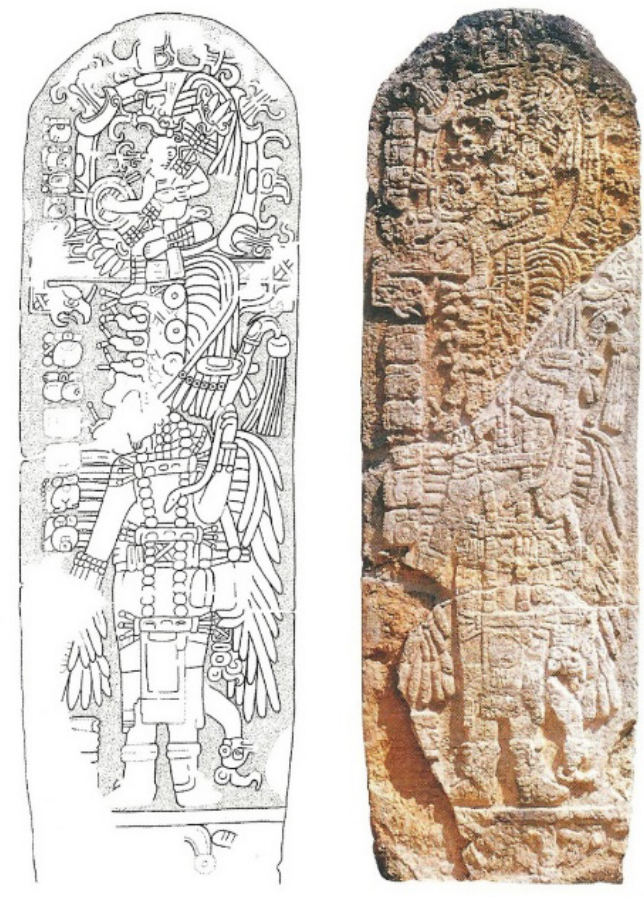

Figura 7: Estela 1 de Ek Balam

Martín (2013) apoyándose en Graniel (2012), menciona que la cualidad de personhood de Ukit Kan Le'k Tok' es fractal permeable, referido al proceso de separación o fragmentación y redistribución de las partes de un todo, en este caso del individuo y sus cualidades, donde las partes están conectadas entre sí. En este caso, Ukit porta el fémur de un ancestro como parte material que lo legitima para gobernar (Graniel 2012:32-33).

La apropiación de la identidad de otra persona, -otro personhood-, mediante la utilización de sus restos, sea como reliquias o como trofeos, fue al parecer algo común entre la élite maya. En 1997, durante el proyecto Oxtancah, en la bahía de Che- tumal, México, dirigido por la Arqlga. Hortencia de Vega Nova, investigadora del Instituto Nacional de Antropología e Historia (INAH), ocurrió un descubrimiento interesante. Los restos de un individuo que traía como pectoral una calota humana fueron encontrados por el autor del presente artículo, al excavar una tumba en el altar central de la plaza principal del sitio. Aunque en un principio se interpretó como un cráneo trofeo, tal vez se trataba de los restos de un ancestro suyo. Este último tipo de datos recuerda en parte la partibilidad en contextos melanesios, que nos menciona Fowler (2004).

Otro trabajo interesante que analiza el personhood en los gobernantes mayas es el de Wendy Concepción Estrada (2015). En su tesis, la autora reporta que las actividades rituales, los conjuros, y las ornamentaciones de los gobernantes del sitio de Yaxchilan fueron factores determinantes en la construcción del ser persona. La autora realiza un cruzamiento interdisciplinario y mediante el análisis iconográfico, epigráfico, arqueológico, arquitectónico y osteológico intenta localizar los elementos que forman parte de la configuración de la personidad de los gobernantes Itzamnaaj B'ahlam y Yaxuun B'ahlam.

En su trabajo, Concepción (2015) considera que la construcción del género en Yaxchilán sirvió como una estrategia complementaria que permitió el flujo de ciertas cualidades entre hombres y mujeres, para mantener un equilibrio en la sociedad maya prehispánica. También menciona que otras entidades anímicas participaron en la construcción de las personidades e identidades de los gobernantes.

La autora considera en su análisis la existencia de un efecto de "extensibilidad" en la configuración humano-animal de la persona y que en la cosmovisión maya contemporánea corresponde a lo que se denomina Uay. Los Uayes o Uayo'ob son entidades anímicas, o co-esencias que juegan un papel muy importante en la configuración del personhood maya. La transformación de una persona en animal o cosa es una forma particular de personhood, que no la tuvo cualquier individuo. La extensibilidad mencionada entonces por Concepción (2015) puede entenderse como el paso de ciertas formas de personidad entre los seres humanos con 
los animales, con las cosas y con la naturaleza, que también puede darse en sentido inverso.

Las prácticas y acciones humanas son determinantes en la conformación de la persona. Concepción (2015:127) lo deja en claro cuando analiza los rituales de entronización, como el momento del cambio de la personidad de los gobernantes. A través de diversas prácticas realizadas durante el ritual la persona sufre ciertos cambios significativos que le permiten ser gobernante, uno de estos es la esencia divina que le da su fuerte relación con la deidad, manifestada en los nuevos ornamentos y títulos utilizados. En el gobernante se mezclan tanto esencias divinas como terrenales. En Yaxchilán, el gobernante entabla relación con el dios $K$ 'awil, deidad asociada con el rayo, el trueno y la lluvia, con las denominadas deidades patronas, ligadas con el pasado de la ciudad y por último con sus propios ancestros (reales o putativos). Estas esencias también se extendieron a las consortes reportadas en el sitio.

Concepción (2015:132) concluye que tzamnaaj $B$ 'ahlam y Yaxuun B'ahlam fueron personajes que no fueron concebidos como individuos delimitados, únicos e indivisibles de la manera en que se concibe a la persona en las sociedades occidentales. La persona es resultado del intercambio de múltiples elementos que logran crear y mantener la identidad personal del gobernante a través de las relaciones y prácticas sociales que entablaron o realizaron durante el rito de entronización, en su vida de gobernante y después de la muerte.

\section{CONCLUSIONES}

Los gobernantes en cualquier momento de la historia y cultura siempre buscan mantener su autoridad y su legitimidad, a través de diferentes medios (Kurnick 2016 en García 2019:141). Los gobernantes del periodo Clásico maya adquirieron estatus divino a través de nombres de otras personas: dioses y ancestros. La apropiación de estos nombres aparece en varios sitios de las tierras bajas mayas, como Calakmul, Ekbalam, Bonampak, Palenque, Yaxchilan y Copán, entre otros.
No obstante, un estudio comprensivo sobre la estructura y significado de los antropónimos todavía está pendiente entre los arqueólogos y epigrafistas mayistas.

Los nombres personales que aparecen en el periodo Clásico consisten en una variedad de elementos que podrían referirse al gobernante maya en sí mismo y como persona. También podría estar mostrando otro modo del personhood en términos de dividuo, pues la persona en sí también es otra y comparte la identidad o cualidad de otras personas humanas o no humanas.

La información epigráfica, iconografía y los contextos mortuorios son las fuentes principales que se tienen en arqueología maya para entender la personalidad, la identidad y el personhood de los individuos. Por tanto, estos estudios pueden enfocarse principalmente en los individuos de la élite. Las personas de estratos o clases sociales inferiores, difícilmente aparecen en las inscripciones epigráficas y sus nombres no son registrados, lo que les impide entrar en escena.

En el caso de los gobernantes mayas es clara la utilización de entidades materiales, espirituales y mágicas para legitimar su persona, su individualidad y agencia. En esta legitimación, sus cualidades de ser también eran transformadas. Las cualidades del sí mismo y su persona eran consolidadas por el rito, la alusión a los ancestros divinos y la apropiación de epítetos de sus dioses. Para ellos era importante consolidar su persona ante la sociedad, por lo que la construcción del cuerpo político debía cumplir con las expectativas y compromisos adquiridos en su relación con lo terrenal y lo no terrenal.

No son muchos los trabajos que tratan el tema que se acaba de exponer, pues, aunque interesante y pertinente no es muy tratado por los arqueólogos que trabajan en el área maya. No obstante, existen muchos datos surgidos de las lecturas epigráficas, análisis iconográficos y reportes arqueológicos que pueden ser de utilidad. Para finalizar hay que comentar que los modelos melanesio e hindú que Fowler (2004) menciona en su libro, podrían ser estudiados y contrastados con el dato arqueológico maya. Con base en la breve revisión que se ha realizado, parece ser que la permeabilidad mela- 
nesia tiende a ser el modelo que se acerca más al caso maya, aunque claro está, falta hacer un estudio exhaustivo que corrobore o no el modelo.

\section{REFERENCIAS BIBLIOGRÁFICAS}

Binford, L. (1971). Mortuary Practices: their Study and their Potential. Approaches to the Social Dimensions of Mortuary Practices, 25, 6-29.

Colas, P. (2003). K'inich and King. Naming self and person among Classic Maya rulers. $A n$ cient Mesoamerica, 14, 269-283.

Concepción, W. (2015). Identidad personal de dos gobernantes mayas de Yaxchilan: Itzamnaaj $B$ 'ahlam y Yaxuun B'ahlam (tesis de grado). Universidad Autónoma de Yucatán, México.

Hernández, H. \& Pool, M. (2010). Identidades y cultura material en la región maya. Mérida: Universidad Autónoma de Yucatán.

Fash, W. (1991). Lineage Patrons and Ancestor Worship among the Classic Maya Nobility: The Case of Copán Structure 9N-82. En Merle Green Robertson and Virginia Miller Fields (eds). Sixth Palenque Round Table, 1986, (pp. 68-80). Norman: University of Oklahoma Press.

Fitzsimmons, J. (1998). Classic Maya Mortuary Anniversaries at Piedras Negras, Guatema1a. Ancient Mesoamerica, 9, 271-278.

Fitzsimmons, J. (2003). Reyes difuntos y costumbres funerarias: Epigrafía y arqueología de la muerte en la sociedad Maya Clásica. En J. Laporte, B. Arroyo, H. Escobedo y H. Mejía (eds.). XVI Simposio de Investigaciones Arqueológicas en Guatemala, (pp. 672-678). Guatemala: Museo Nacional de Arqueología y Etnología.

Fowler, Ch. (2004). The Archaeology of Personhood. An anthropological approach. Lon- don: Routldge.

García, H. (2019). La montaña sagrada. Aspectos sobre la legitimación del poder en el Clásico maya. Estudios de cultura maya, LIII, 139172.

Graniel, M. (2012). Estudios del personhood en las tierras bajas centrales mayas durante el Clásico (tesis de grado). Universidad Autónoma de Yucatán, México.

Hocart, A. (1970). Kings and Councilliors: An Essay in the Comparative Anatomy of $\mathrm{Hu}$ man Society. Chicago: University of Chicago Press.

Houtson, S. \& Stuart, D. (1996). Of Gods, Glyphs and Kings: Divinity and Rulership among the Classic Maya. Antiquity, 70, 289-312.

Kantorowicz, E. (1957). The Kings Two Bodies: A Study in Mediaeval Political Theology. Princeton: Princeton University Press.

Lacadena, A. (2003). El Corpus Glifico de Ek' Balam, Yucatán, México. México: FAMSI. Recuperado de http://www.famsi.org/reports/01057es/

Martin, S. \& Grube, N. (2000). Chronicle of the Maya kings and queens. London: K R, Londres, Thames and Hudson.

Martín, G. (2013). Análisis de la identidad individual de los gobernantes mayas del Clásico. Los casos de Ukit Kan Lek Tok', K'inich Janaab Pakal y K'inich Yax K'uk Mo (tesis de grado). Universidad Autónoma de Yucatán, México.

Méndez, L. (1992). I Seminario Sobre Identidad. México: Instituto de Investigaciones Antropológicas, UNAM.

Pool, M. (2003). Sistemas de descendencia y parentesco entre los mayas prehispánicos. Crítica al modelo de linaje (tesis de maestría). Universidad Autónoma de Yucatán, México.

Ricoeur, P. (2003). Sí mismo como otro. Madrid: Siglo XXI. 